\title{
A produção científica da educação básica sob a perspectiva de Hugh Lacey
}

\author{
The scientific production of basic education from \\ the perspective of Hugh Lacey
}

\author{
Prof ${ }^{\text {a }}$ Dra. Joelma dos Santos \\ Garcia Delgado \\ Instituto Federal de Educação, \\ Ciência e Tecnologia de Mato \\ Grosso do Sul \\ profjoelmabio@gmail.com \\ ORCID \\ http://orcid.org/0000-0002- \\ 5097-7042

\section{Prof $^{a}$. Dra. Vera de Mattos Machado} \\ Universidade Federal de Mato \\ Grosso do Sul \\ veramattosmachado1@gmail. \\ com \\ ORCID \\ https://orcid.org/0000-0002- \\ 5595-400x
}

Recebido em:31/03/2021

Aceito em:11/10/2021

\section{Resumo}

O objetivo do presente artigo foi refletir, a partir do referencial de Hugh Lacey as tendências relacionadas aos valores sociais da produção científica da educação básica brasileira divulgada em Feiras e Mostras. Por meio de metodologia qualitativa, foi analisado resumos de projetos premiados pela Feira Brasileira de Ciência e Engenharia do ano de 2017. E os resultados evidenciaram uma tendência à valorização do desenvolvimento modernizador, ligada à economia capitalista mundial, desenvolvida e comprovada por meio de estratégias descontextualizadas. Em contraposição a esses fatos, sugere-se uma maior valorização ambiental como critério de avaliação, um olhar mais crítico frente ao aspecto mercadológico da Ciência a formação de uma autoconsciência crítica desde a educação básica.

Palavras-chave: Filosofia da Ciência; Valores da Ciência; Divulgação científica; Feira científica e tecnológica; FEBRACE.

\section{Abstract}

The objective of this article was to reflect, based on Hugh Lacey's referential, trends related to social values in the scientific production of Brazilian basic education disseminated in Fairs and Exhibitions. Through a qualitative methodology, summaries of projects awarded by the Brazilian Science and Engineering Fair in 2017 were analyzed. And the results evidenced a tendency to valorize the modernizing development, linked to the world capitalist economy, developed and proven through decontextualized strategies. In opposition to these facts, it is suggested a greater environmental valuation as an evaluation criterion, a more critical look at the market aspect of Science and to form a critical self-awareness from the basic education.

Keywords: Philosophy of Science; Science Values; Scientific divulgation; Scientific and technological fair; FEBRACE. 


\section{Introdução}

A Ciência pode ser compreendida como um fenômeno social antigo que vem sendo transformado ao longo da história, alcançando atualmente o status de ciência experimental moderna. A tecnologia e a Ciência têm sido reconhecidas como essenciais ao desenvolvimento econômico, cultural e social, estabelecendo-se até mesmo uma relação de dependência cada vez maior entre elas e a sociedade (GERMANO, 2011).

No Brasil, durante os anos 1980 e 1990 "a globalização da economia e a homogeneização dos critérios de competitividade passaram a influenciar fortemente a produção científica e tecnológica brasileira, segundo princípios neoliberais", um cenário imposto pelo capital internacional (NASCIMENTO et al., 2010, p. 226227). A essas produções científicas tem-se atribuído uma ampla legitimidade, internalizando um profundo valor pragmático, com a tendência de aceitar que o futuro será moldado em resposta a ela (LACEY, 2000).

Nesse contexto, a educação básica brasileira tem experimentado momentos que envolvem a produção científica e sua divulgação por meio de pesquisas e realização de Feiras e Mostras de cunho científico e tecnológico. Nesse sentido, a principal questão deste trabalho se relaciona a: quais os valores científicos sociais que têm sido relevantes para avaliação e premiação nessas feiras? Dessa forma, o objetivo dessa foi refletir, segundo o referencial teórico de Hugh Lacey, sobre as tendências desses valores na produção científica de estudantes da educação básica evidenciados por meio das premiações da Feira Brasileira de Ciência e Engenharia (FEBRACE) em sua 15a edição (2017).

\section{A epistemologia de Hugh Lacey}

O filósofo australiano e naturalizado americano, Hugh Lacey (2007; 2009b), tem realizado uma expressiva reflexão sobre a Ciência moderna que, segundo ele, tem produzido grande quantidade de conhecimento confiável sobre os fenômenos do mundo, com uma considerável parcela servindo de base para aplicações na tecnologia, na medicina, dentre outras aplicações, contribuindo com a transformação e melhoria do mundo.

Em suas publicações, Lacey (2006; 2007; 2008a; 2008b; 2009b), levanta questões de como a Ciência incorpora os valores da autonomia, da objetividade e da neutralidade. E para melhor entendimento, se faz necessário discutir mesmo que sucintamente tais valores - aspirações ou ideais - das práticas científicas que permeiam as publicações desse teórico.

Assim, em relação a autonomia, Lacey explana que os:

[...] problemas de metodologia científica e critérios para avaliação do conhecimento científico encontram-se fora da esfera de qualquer perspectiva ética (religiosa, política, social e econômica) e não dependem de preferências pessoais; as prioridades da pesquisa, para o empreendimento científico como um todo, não devem ser moldadas por alguma perspectiva valorativa particular (LACEY, 2007, p. 2).

Sobre a objetividade, refere que as práticas científicas são imparciais, ou seja, que uma teoria só é aceita após ter sido rigorosamente testada via procedimentos de pesquisa empírica, sob critérios estritamente cognitivos, sem refletir valores sociais e éticos particulares (LACEY, 2007; 2008b). Já a neutralidade é um valor que considera que os resultados científicos "não favorecem algumas perspectivas éticas em prejuízo de outras, seja através de suas implicações lógicas, seja através das consequências decorrentes de suas aplicações" (LACEY, 2007, p. 2).

Dentre esses valores, conforme Lacey (2008a, p. 301) a autonomia sempre foi o mais delicado, pois ela precisa de "apoio externo ao mesmo tempo em que pretende rejeitar a interferência externa, [...] a autonomia tem sido frequentemente subordinada a interesses externos". Ele diz que a pesquisa científica tem sido cada vez mais controlada por corporações e agências governamentais sensíveis aos interesses corporativos, denominando-a de Ciência do interesse privado (LACEY, 2009b; 2009c). 
O autor também aponta a contribuição da Ciência para a crise ambiental, em que as limitações da neutralidade se acentuam devido ao interesse privado, mostrando que nem sempre a Ciência vive de acordo com seus ideais. Esclarece assim, que se os valores sociais influenciam a atividade científica e que a objetividade, a neutralidade e a autonomia são ideais, muitas vezes, próximos, mas muitas vezes, também ignorados (LACEY, 2008b).

Em suas reflexões, Lacey compara a Ciência por meio de entendimento materialista da qual faz parte a maioria das teorias científicas modernas, sendo desenvolvida e comprovada por meio de estratégias descontextualizadas, que restringem os tipos de teorias consideradas e selecionam os tipos de dados empíricos relevantes para sua comprovação (LACEY, 2008b; 2019). O filósofo compreende que a tradição da ciência moderna é amplamente afirmada em ideias de que a adoção das estratégias descontextualizadas caracteriza e é suficiente na investigação científica (LACEY, 2019). Segundo Lacey:

A pesquisa científica moderna tendeu a adotar virtualmente apenas variedades de estratégias que se encaixem (no que agora eu chamo) de abordagem descontextualizada. (Em documentos anteriores me referi a elas como 'estratégias materialistas'). Sob essas estratégias, teorias são restringidas para que possam representar a estrutura subjacente, a interação, o processo e a lei dos fenômenos, dissociadas de seus contextos ecológico, social e humano (LACEY,2009c, p. 625).

Por outro lado, a crítica Pós-Moderna ${ }^{1}$ suspeita da imparcialidade e neutralidade defendidas pelo entendimento descontextualizado ao afirmar que a Ciência não está livre de valores, identificando a presença de valores históricos e sociais na escolha de teorias científicas. Dessa forma, não se representa "o mundo tal como ele é, mas uma imagem do mundo no qual, em certa medida, incidem nossa presença e nossos valores" (LACEY, 2008b, p. 37).

A respeito do tipo de pesquisa que se tem realizado no Brasil, Lacey (2008b) coloca claramente que ela tem servido para ampliar a capacidade do homem em dominar a natureza e que estão nas mãos do Capital. E é justamente nesse contexto que Lacey reflete que: a Ciência como praticada atualmente não produz o conhecimento necessário para lidar com a atual crise ambiental, incluindo suas dimensões humana e social, pautando sua reflexão filosófica questionando sobre quais deveriam ser as prioridades da atividade científica e também quanto aos seus valores (LACEY, 2007). Visto que:

[...] as aplicações do conhecimento científico obviamente são abertas à avaliação ética, assim como os métodos usados na pesquisa e a escolha das prioridades para a investigação. Além disso, diz-se que a pesquisa científica, em si mesma, tem valor ético por conta (supostamente) de sua contribuição para o cultivo do bem-estar humano - o conhecimento científico pertence ao patrimônio compartilhado da humanidade! (LACEY, 2009, p. 1).

Dessa forma, ele apresenta uma proposta que "representa um ponto de vista que rejeita a dissociação entre esses assuntos e as questões sobre como os valores éticos e sociais têm (e devem ter) influência no processo total da pesquisa", dentre elas recomenda que a pesquisa científica respeite o princípio de precaução (PP) (LACEY, 2007, p. 1). Tal princípio prevê a condução de estudos ecológicos, sociais e outros estudos

1 Como exemplo, podemos tomar a renúncia da questões de natureza metafísica e uma preocupação com problemas relacionados à linguagem e às possibilidades do conhecimento interculturais e contra o apagamento de vivências e saberes das ditas minorias (grupos marginalizados dentro de uma sociedade devido aos aspectos econômicos, sociais, culturais, físicos ou religiosos) que foram silenciadas com uma desculpa sobre valor intelectual que hoje se é considerada pelos pós-modernos como uma forma de preconceito e escolha política e social. 
que possam ser relevantes, a fim de verificar riscos antecipados, incluindo aqueles que são socioeconômicos (LACEY, 2006; 2009b). Conforme Lacey, o princípio de precaução recomenda:

cautela e atraso face à aplicação tecnológica de resultados científicos bem confirmados; • importância de empreender investigação em áreas que não podem ser investigadas adequadamente utilizando só as metodologias de pesquisa que produzem o conhecimento que informa as inovações tecnocientíficas (LACEY, 2007, p. 2).

E o PP comporta investigações que identificariam riscos à luz dos juízos éticos baseados em recomendações como direitos humanos, responsabilidade ambiental, desenvolvimento sustentável, equidade intergeracional e democracia participativa que, no entanto, são muito pouco investigados (LACEY, 2007; 2009b).

Entretanto, existe muita oposição ao PP em instituições científicas, pois dizem que a autonomia da pesquisa científica é limitada, já que subordina os objetivos científicos aos éticos e recomenda atraso nas aplicações tecnocientíficas, pois terá que destinar tempo para verificar, por exemplo, riscos ecológicos e sociais a longo prazo (LACEY, 2007).

Todavia, de acordo com Lacey (2007), grande parte da pesquisa tecnocientífica é atualmente realizada de acordo com o Princípio do pressuposto da legitimidade das inovações tecnocientíficas (PLT), que é oposto ao PP. A PLT defende que uma inovação tecnocientífica é legítima se houver uma aplicação de acordo com a objetividade, priorizando as soluções para os grandes problemas mundiais.

Nesse sentido, Lacey (2008a) indica a necessidade de se lutar por uma mudança de direção da produção de conhecimento científico, já que este progresso nem sempre atende aos interesses da sociedade brasileira. Sugere também questionar as possibilidades com vistas à melhoria do bem-estar de todos de uma determinada região, diferentemente do que tem acontecido em virtude das estratégias descontextualizadas.

Considerando esses aspectos, há necessidade de interferência prévia nos rumos que devem ser dados às investigações, e em que direção os esforços de resposta devem ser concentrados, sendo que o desconhecimento das conquistas culturais humanas causa prejuízos, que podem ser ampliados em uma sociedade cada vez mais submetida aos domínios da Ciência e da tecnologia. Nesse contexto, considera-se fundamental que todo cidadão tenha uma educação mínima acerca da Ciência e da tecnologia a fim de permitir conhecer seus métodos, riscos, incertezas, interesses, entre outros. (GERMANO, 2011)

Assim sendo, Lacey (2008b, p. 187) inclui como tarefa da educação científica a necessidade de gerar "a autoconsciência crítica sobre o caráter da atividade científica e de suas aplicações e sobre as escolhas com as quais se defrontam seus participantes responsáveis".

\section{Sobre a Feira Brasileira de Ciência e Engenharia (FEBRACE)}

Na medida em que isso tem sobrevindo, também se observa a crescente importância no ensino de Ciências, resultando em inúmeros movimentos de transformação do ensino, como mostram as reformas educacionais (KRASILCHIK, 2000). Há registros que, no ensino de Ciências, a neutralidade da Ciência era colocada em evidência por meio de um ensino verbalizado, teórico e conteúdos focados no produto final das atividades científicas, apontados no contexto brasileiro até meados dos anos 50 (BRASIL, 2006). Mas a partir da década de 60 iniciou-se um movimento com vistas à promoção e consolidação de "inúmeras atividades voltadas para a prática do Ensino de Ciências, como, por exemplo, a divulgação científica e preparação de jovens da escola primária e secundária na iniciação científica [...] entre as quais se destacaram as Feiras de Ciências" (BRASIL, 2006, p. 13).

Há cerca de dez anos, essas feiras, eram um espaço de divulgação da produção científica, já eram consideradas como um movimento vivo em todo o Brasil, além de acontecer também em vários países da América Latina e do mundo, de forma a superar a ideia da Ciência como produto acabado, mas sim como um 
processo, uma ciência voltada à resolução de problemas, com a apresentação de vários trabalhos direcionados às soluções em benefício da própria comunidade em que esses estudantes estão inseridos (BRASIL, 2006), destacando a relação aluno, escola e comunidade:

Embora numa feira apareçam trabalhos de muitos tipos [...], atualmente a ênfase maior passou a ser de cunho social em que os alunos levantam a problemática e, sempre que possível, buscam soluções para as dificuldades mais prementes da comunidade, evidenciando o caráter político da educação. (BRASIL, 2006, p. 21)

Dentre as feiras desenvolvidas no Brasil, apresentamos a Feira Brasileira de Ciência e Engenharia (FEBRACE), na qual estudantes da educação básica apresentam resultados de suas pesquisas, sendo o evento organizado e executado pela Escola Politécnica da Universidade de São Paulo (USP) (BRASIL, 2006). Iniciada em 2003, realizou sua $15^{\text {a }}$ edição em março de 2017, envolvendo projetos nas áreas de Ciências Agrárias, Ciências Biológicas, Ciências da Saúde, Ciências Exatas e da Terra, Ciências Humanas, Ciências Sociais Aplicadas e Engenharia.

Tais projetos devem ser realizados por no máximo três estudantes e submetidos por meio de cadastro online do site da FEBRACE com prévia seleção dos finalistas, ou por meio de seleção em feiras afiliadas. Para o referido cadastro são necessárias informações: plano de pesquisa, formulários de informações do projeto, resumo do projeto e relatório do projeto. Outros documentos também podem ser obrigatórios conforme exigências específicas da pesquisa, por envolver animais vertebrados ou seres humanos, por exemplo. Caso o projeto seja aprovado, deverá ser enviado, conforme calendário divulgado no site, o artigo do projeto e realizar pagamento da taxa (FEBRACE, 2017c). Cabe aqui ressaltarmos os objetivos apresentados por essa:

1) Estimular novas vocações em Ciências e Engenharia através do desenvolvimento de projetos criativos e inovadores. 2) Aproximar as escolas públicas e privadas das Universidades, criando oportunidades de interação espontânea entre os estudantes e professores das escolas com a comunidade universitária (estudantes, professores, funcionários), para uma melhor compreensão dos papéis das Universidades em Ensino, Pesquisa, Cultura e Extensão. 3) Criar uma oportunidade para jovens pré-universitários brasileiros entrarem em contato com diferentes culturas e estarem próximos de reconhecidos cientistas (FEBRACE, 2017c).

A partir das propostas apresentadas aqui, percebe-se que a produção científica está presente na educação básica, sendo a FEBRACE, um exemplo, dessa estratégia de promoção e divulgação dessa Ciência produzida por estudantes do Ensino Médio. Considerando esses aspectos que o presente artigo objetiva entender as tendências dos valores na produção científica de estudantes da educação básica por meio das premiações da 15ª edição da FEBRACE, a luz das concepções do teórico Hugh Lacey.

\section{Metodologia}

Trata-se de uma pesquisa aplicada de natureza qualitativa, e com objetivo exploratório. O instrumento de coleta de dados é do tipo documental, tendo como fonte os resumos (único documento acessível em publicação) dos trabalhos finalistas que foram premiados pela organização FEBRACE em 2017, totalizando 59 resumos analisados.

Como instrumento de análise de dados utilizou-se os pressupostos da Análise de Conteúdo de Bardin (1977), pois esses permitem classificar os componentes do significado das mensagens do conteúdo extraído. É um conjunto de técnicas de análise das comunicações que classificam "os diferentes elementos nas diversas gavetas segundo critérios susceptíveis de fazer surgir um sentido capaz de introduzir uma certa ordem na confusão inicial" (Bardin, 1977, p. 37). Assim, segundo Bardin (1977), o analista manipula os dados do emissor 
para inferir certos conhecimentos, recorrendo a indicadores (quantitativos ou não) e seguindo critérios de organização: a pré-análise, a exploração do material e o tratamento dos resultados.

A escolha das categorias foi previamente elaborada com base nos pressupostos epistemológicos de Hugh Lacey discorridos no referencial teórico deste artigo, compilando-se assim em um roteiro com quatro perguntas sobre valores sociais que foram categorizadas a partir da leitura dos resumos premiados. As respostas as categorias correspondem a: $\operatorname{sim}(\mathrm{S})$, não $(\mathrm{N})$ ou dados insuficientes (-) para as questões de um a três, e para a questão número quatro, foram princípio de precaução $(\mathrm{PP})$ e/ou Princípio de pressuposto da legitimidade das inovações tecnocientíficas (PLT). Já as questões formuladas foram:

1. Possui possibilidade de patente e/ou está ligada à aplicabilidade e ao comércio (LACEY, 2008a)?

2. Visa atender a toda humanidade, incluindo, por exemplo, questões sobre fome/produção de alimento, saúde pública, saneamento básico e educação (LACEY, 2008a)? Há pelo menos alguma preocupação com a população menos favorecida (LACEY, 2008b)?

3. Evidencia alguma preocupação ambiental (LACEY, 2008b, 2012)?

4. Relata algum indício do princípio de precaução (PP) ou segue o Princípio de pressuposto da legitimidade das inovações tecnocientíficas (PLT) (LACEY, 2006; 2007)?

É válido reiterar que os resultados aqui apresentados foram pautados na análise de resumos disponíveis, portanto, nossas inferências são especificas e passíveis de complementações. O propósito se consolida em refletir acerca desse panorama que nos servirá para reflexões atuais e futuras sobre as tendências dos valores da ciência desde a educação básica, bem como intenta apontar direções em busca da formação de estudantes com autoconsciência crítica, uma necessidade apontada por Lacey (2008b). Assim, também se optou por apresentar um panorama quantitativo quanto à totalidade das respostas obtidas para as questões expostas acima, proporcionando uma visão geral da análise.

\section{Resultados e Discussão}

O Relatório de Atividades da FEBRACE do ano de 2017, publicado em seu site mostra que a feira teve alcance de 763 estudantes finalistas que apresentaram 346 projetos de pesquisa investigativa, provindos tanto da submissão direta como de feiras afiliadas pelo Brasil. Os finalistas vieram de 267 cidades distribuídas em 27 estados brasileiros (FEBRACE,2017b).

E no que tange à avaliação dos projetos de pesquisa consta que a comissão avaliadora foi formada por "professores da USP e de Universidades parceiras, mestres e doutores, o que garante qualidade e credibilidade científica à avaliação"; que o "nível de especialização do avaliador na área do projeto, bem como os anos de experiência avaliando os projetos participantes da FEBRACE, é levado em consideração na ponderação das médias finais atribuídas"; e os critérios de avaliação incluem a "atitude científica, habilidades, criatividade e inovação, profundidade do método científico / método de engenharia, relatório, diário de bordo, pôster, apresentação oral, atitude empreendedora, relevância social e trabalho em grupo" (FEBRACE, 2017b, p. 12).

A fim de facilitar a citação dos trabalhos, identificamos com uma sigla, sendo a inicial "CA" provinda da área, no caso, das Ciências Agrárias. A numeração corresponde ao lugar de premiação. E se houvesse mais de um trabalho premiado em uma mesma colocação, acrescentou-se as letras a, b, c, até finalizar a relação da premiação correspondente.

\section{Ciências Agrárias}

Traremos nossa análise por área, iniciando com Ciências Agrárias (CA), que de 28 projetos finalistas, cinco foram premiados, como mostra o Quadro 1 abaixo. 
Quadro 1 - Lista de projetos premiados em Ciências Agrárias pela FEBRACE 2017 e inferências quanto às questões propostas.

\begin{tabular}{|c|c|c|c|c|c|c|}
\hline \multirow[b]{2}{*}{ Lugar } & \multirow[b]{2}{*}{ Projeto } & \multirow[b]{2}{*}{ Sigla } & \multicolumn{4}{|c|}{ Questões } \\
\hline & & & 1 & 2 & 3 & 4 \\
\hline $1^{\circ}$ & $\begin{array}{l}\text { Transformação dos resíduos agroindustriais do maracujá em filmes } \\
\text { plásticos biodegradáveis }\end{array}$ & CA1 & $S$ & $\mathrm{~N}$ & $S$ & PLT \\
\hline $2^{\circ}$ & $\begin{array}{l}\text { Madeco Sabugosa: madeira ecológica, proveniente da reutilização } \\
\text { do sabugo e da palha do milho }\end{array}$ & CA2 & $S$ & $\mathrm{~N}$ & $S$ & PLT \\
\hline $3^{\circ}$ & $\begin{array}{l}\text { Biomassa de banana verde (Musa spp) como fonte alternativa } \\
\text { de alimentação - II fase }\end{array}$ & CA3 & S & S & S & - \\
\hline $4^{\circ}$ & $\begin{array}{l}\text { Inserção de insetos na alimentação humana como alternativa } \\
\text { nutricional }\end{array}$ & CA4a & $S$ & $S$ & $\mathrm{~N}$ & $\mathrm{PP}$ \\
\hline $4^{\circ}$ & $\begin{array}{l}\text { Aumento na produção agrícola a partir da utilização de gás } \\
\text { carbônico no tratamento de sementes. }\end{array}$ & CA4b & S & S & $\mathrm{N}$ & PLT \\
\hline
\end{tabular}

Fonte: Elaboração própria.

O Quadro 1 revela que todos os projetos possuem possibilidade de patente e/ou comercial, apoiando a tendência materialista relatada por Lacey (2008b). Em relação à questão 2, destacamos o seguinte trecho retirado do projeto CA4b: "Pensando nas necessidades futuras de aumentar a produção agrícola para suprir a necessidade do aumento populacional" (FREBRACE, 2017a, p. 172). Esse trabalho apresenta tal preocupação e realiza seus testes com sementes industriais e crioulas, sendo que em suas conclusões diz que "com o uso de $\mathrm{CO}_{2}$, é possível aumentar a produção agrícola, além de reduzir os custos, pois as sementes tratadas industrialmente apresentam um custo mais alto quando comparadas às sem tratamento".

O que colocamos à reflexão é que, mesmo realizando testes com sementes não industrializadas, a partir do momento que uma proposta como essa é pensada e justificada pela comercialização, poderá atender ao que Lacey (2007) chama de interesse privado ao invés de possibilitar o alcance de todos. Lacey (2000, 2008b) fundamenta várias discussões justamente na revolução verde, a qual se preocupava com a fome do mundo, mas acabou por atender a um fim capitalista.

Destacamos também o trabalho CA4a, que foi um dos poucos a considerar o Princípio de Precaução, que mesmo tendo resultados positivos, finaliza o seu resumo com a seguinte frase: "para que os insetos sejam inseridos na alimentação humana ainda há muitos aspectos a serem analisados pelos pesquisadores da área" (FREBRACE, 2017a, p. 183). A questão colocada em pauta aqui é se tais pesquisadores realmente reconheceram a influência de valores éticos e sociais em sua proposta. Entretanto, a menção a essa precaução em um espaço tão restrito, que é o resumo, já mostra a existência de reflexões aproximadas ao PP.

\section{Ciências Biológicas}

$\mathrm{Na}$ área de Ciências Biológicas (CB), dos 55 projetos finalistas, nove foram premiados (Quadro 2).

Quadro 2 - Lista de projetos premiados em Ciências Biológicas pela FEBRACE 2017 e inferências quanto às questões acima apresentadas.

\begin{tabular}{l|l|l|l|l|l|l}
\hline \multicolumn{2}{l|}{} & \multicolumn{4}{|c}{ Questões } \\
\hline Lugar & Projeto & Sigla & $\mathbf{1}$ & $\mathbf{2}$ & $\mathbf{3}$ & 4 \\
\hline $1^{\circ}$ & $\begin{array}{l}\text { Eucalyptusaligna: uma nova alternativa para o controle do Aedes } \\
\text { aegypti }\end{array}$ & CB1a & S & S & N & PLT \\
\hline $1^{\text {o }}$ & $\begin{array}{l}\text { Redes biológicas e a relação entre genes e funções mitocondriais } \\
\text { com o transtorno obsessivo compulsivo }\end{array}$ & CB1b & - & S & N & - \\
\hline
\end{tabular}




\begin{tabular}{l|l|l|l|l|l|l}
\hline $2^{\circ}$ & $\begin{array}{l}\text { Embacaju: embalagem biodegradável produzida a partir do reapro- } \\
\text { veitamento da folha do caju (Anacardium occidentale) }\end{array}$ & $\mathrm{CB} 2 \mathrm{a}$ & $\mathrm{S}$ & $\mathrm{N}$ & $\mathrm{S}$ & $\mathrm{PLT}$ \\
\hline $2^{\circ}$ & A administração e tratamento de arroios urbanos & $\mathrm{CB} 2 \mathrm{~b}$ & $\mathrm{~S}$ & $\mathrm{~S}$ & $\mathrm{~S}$ & $\mathrm{PP}$ \\
\hline $3^{\circ}$ & Fita reagente para detectar resíduos de agrotóxicos em hortaliças & $\mathrm{CB} 3 \mathrm{a}$ & $\mathrm{S}$ & $\mathrm{S}$ & $\mathrm{N}$ & $\mathrm{PLT}$ \\
\hline $3^{\circ}$ & $\begin{array}{l}\text { Análise da ação da papaína extraída do mamão sobre a integridade } \\
\text { dos ovos do verme Schistosoma mansoni }\end{array}$ & $\mathrm{CB} 3 \mathrm{~b}$ & $\mathrm{~S}$ & $\mathrm{~S}$ & $\mathrm{~N}$ & $\mathrm{PP}$ \\
\hline $4^{\circ}$ & $\begin{array}{l}\text { Propriedades do extrato glicólico feito à base da casca do nem } \\
\text { (Azadirachta indica). }\end{array}$ & $\mathrm{CB} 4 \mathrm{a}$ & $\mathrm{S}$ & $\mathrm{S}$ & $\mathrm{N}$ & $\mathrm{PLT}$ \\
\hline $4^{\text {o }}$ & $\begin{array}{l}\text { Fish Data: sistema web para armazenamento, gerenciamento e vi- } \\
\text { sualização de dados biológicos. }\end{array}$ & $\mathrm{CB} 4 \mathrm{~b}$ & $\mathrm{~S}$ & - & $\mathrm{S}$ & $\mathrm{PLT}$ \\
\hline $4^{\circ}$ & $\begin{array}{l}\text { Efeito da temperatura no desempenho de Macrobrachium amazoni- } \\
\text { cum em sistema de recirculação e extração da quitosana a partir do } \\
\text { cefalotórax para produção de biomembrana }\end{array}$ & $\mathrm{CB} 4 \mathrm{c}$ & $\mathrm{S}$ & - & $\mathrm{S}$ & PLT \\
\hline
\end{tabular}

Fonte: Elaboração própria.

Exceto para CB1b, os demais projetos possuem a possibilidade de patente e/ou comercialização, aproximando ao observado para a área de Ciências Agrárias. Destacamos nossa inferência ao projeto CB2b que se aproxima superficialmente ao PP, de maneira a englobar ações da própria proposta, como relata: "foram observadas também questões relativas ao impacto que esse filtro traria em nossa sociedade" e "foram analisados os resultados obtidos [...] como todas as suas características não só positivas, como também negativas, seus pontos fracos e fortes e, principalmente, sua efetividade" (FEBRACE, 2017a, p. 81).

A partir dos pressupostos baseados em Lacey (2007) o PP causaria atraso na implementação e observamos que provavelmente o projeto em questão deveria investigar de forma mais ampla para concluir tais afirmações. Mas queremos validar a atitude proposta, como um indício de que tais pesquisadores consideram importante essa verificação. Em contradição, inferimos que CB4a segue PLT, visto que finaliza seu resumo: "obtivemos resultados satisfatórios em ambos os testes, provando assim nossa hipótese inicial" (FEBRACE, 2017a, p. 128). Assim, a CB4a evidencia claramente que não há a necessidade de investigação adicional.

Verificamos também que CB3a faz referência à produção de orgânicos e se preocupa com o controle de qualidade desses produtos: "verificando desta forma se a hortaliça é orgânica ou não" (FEBRACE, 2017a, p. 112), um projeto considerado preocupado com a saúde humana, o que o classificou positivamente na questão quanto ao atendimento a toda humanidade. Já o projeto CB4c esteve atento à questão ambiental por reutilizar partes dos camarões para confecção de biomembranas.

\section{Ciências da Saúde}

Dentre os 26 finalistas na área de Ciências da Saúde (CS), cinco foram premiados, como se pode observar no quadro 3.

Quadro 3 - Lista de projetos premiados em Ciências da Saúde pela FEBRACE 2017 e inferências quanto às questões acima apresentadas.

\begin{tabular}{l|l|l|l|l|l|l}
\multicolumn{2}{l|}{} & \multicolumn{5}{|c}{ Questões } \\
\hline Lugar & Projeto & Sigla & $\mathbf{1}$ & $\mathbf{2}$ & $\mathbf{3}$ & 4 \\
\hline $1^{\circ}$ & $\begin{array}{l}\text { Utilização de metabólitos microbianos no desenvolvimento de } \\
\text { alternativa para combate de Klebsiella pneumoniae }\end{array}$ & CS1 & S & S & N & - \\
\hline $2^{\circ}$ & $\begin{array}{l}\text { Avaliação do detergente mais eficiente para descelularização } \\
\text { pancreática visando a criação de um pâncreas bioartificial para o } \\
\text { tratamento do diabetes tipo 1 }\end{array}$ & CS2 & S & S & N & PLT \\
\hline
\end{tabular}




\begin{tabular}{l|l|l|l|l|l|l}
\hline $3^{\mathrm{o}}$ & Formulações extemporâneas para pediatria: importância e riscos & $\mathrm{CS} 3$ & $\mathrm{~N}$ & $\mathrm{~S}$ & $\mathrm{~N}$ & - \\
\hline $4^{\mathrm{o}}$ & $\begin{array}{l}\text { Desenvolvimento de um protótipo portátil para determinação de } \\
\text { lactose em produtos lácteos. }\end{array}$ & $\mathrm{CS} 4 \mathrm{a}$ & $\mathrm{S}$ & $\mathrm{S}$ & $\mathrm{N}$ & $\mathrm{PLT} / \mathrm{PP}$ \\
\hline $4^{\mathrm{o}}$ & $\begin{array}{l}\text { Correlação do perfil cognitivo e expressão gênica periférica de } \\
\text { pacientes com transtorno obsessivo compulsivo, de irmãos e con- } \\
\text { troles - parte I }\end{array}$ & $\mathrm{CS} 4 \mathrm{~b}$ & $\mathrm{~N}$ & $\mathrm{~S}$ & $\mathrm{~N}$ & - \\
\hline
\end{tabular}

Fonte: Elaboração própria.

Os primeiros projetos não foram considerados como patenteáveis e/ou comercializáveis. OCS3, por exemplo, objetivou investigar o preparo de formulações extemporâneas em hospitais públicos e particulares do Rio de Janeiro, aplicando questionários aos profissionais de saúde envolvidos, identificando a "necessidade de estudos para avaliar a eficácia das formulações manipuladas [...], sendo importante uniformizar o preparo e garantir a segurança dos pacientes" (FEBRACE, 2017a, p. 154).

Não respondemos em qual princípio pertence o CS1 (se PP ou PLT) pois, mesmo não fazendo referência a novos estudos, finaliza seu resumo de forma sugestiva a PP: "Este estudo demonstra que é possível se obter uma alternativa à base de compostos naturais no controle de Klebsiella pneumoniae" (FEBRACE, 2017a, p. 164). Mesmo considerando uma forma comedida em sua escrita, não nos posicionamos acerca desse princípio.

É importante destacarmos no projeto CS3 indícios em seus resultados sobre a necessidade de realização de pesquisas, aproximando-o ao princípio de precaução, relacionado à saúde humana acerca do preparo de medicamentos extemporâneos e, como evidencia o título, mostra que são necessárias investigações por que há riscos: "A necessidade de estudos para avaliar a eficácia das formulações manipuladas foi identificada" (FEBRACE, 2017a, p. 154).

Para classificar CS4a como PLT/PP buscamos no dicionário o significado de "protótipo", que para a indústria tecnológica refere-se: "a primeira versão de um produto, fabricado industrialmente ou de modo artesanal, segundo especificações de um projeto", o qual pode servir para futuros testes ou como modelos (AULETE DIGITAL, 2017). Nossa qualificação se baseia na questão que mesmo que seja para testes, acreditamos que esses testes não sejam tão abrangentes como sugere Lacey (2007), mas como existe essa condição futura exploratória, inferimos como PP e PLT. Outros trabalhos, apresentados a seguir, também elaboraram protótipo.

\section{Ciências Ekatas e da Terra}

Em Ciências Exatas e da Terra (CE), foram 76 projetos finalistas e 13 premiações, conforme mostra o Quadro 4.

Quadro 4 - Lista de projetos premiados em Ciências Exatas e da Terra pela FEBRACE 2017 e inferências quanto às questões acima apresentadas.

\section{Questões}

\begin{tabular}{l|l|l|l|l|l|l}
\hline Lugar & Projeto & Sigla & $\mathbf{1}$ & $\mathbf{2}$ & $\mathbf{3}$ & $\mathbf{4}$ \\
\hline $1^{\circ}$ & Simulação da dispersão do Aedes aegypti usando autômatos celulares & CE1a & S & S & N & PLT \\
\hline $1^{\circ}$ & Resina lignofenólica com uso de rejeito industrial & CE1b & S & N & S & PLT \\
\hline $2^{\circ}$ & $\begin{array}{l}\text { Aproveitamento do pó obtido do beneficiamento da casca do coco } \\
\text { verde no abrandamento de água dura }\end{array}$ & CE2a & S & S & S & PLT \\
\hline $2^{\circ}$ & Obtenção de elemento filtrante de metais pesados à base de quitosana & CE2b & S & N & S & PLT \\
\hline $2^{\circ}$ & $\begin{array}{l}\text { Produção de tinta à base de dióxido de titânio capaz de transformar } \\
\text { poluentes em gases inofensivos }\end{array}$ & CE2c & S & N & S & PLT \\
\hline
\end{tabular}




\begin{tabular}{l|l|l|l|l|l|l}
\hline $3^{\circ}$ & $\begin{array}{l}\text { Automatização da produção de sabão - uma solução de sustentabili- } \\
\text { dade alternativa }\end{array}$ & CE3a & S & N & S & $\begin{array}{l}\text { PP/ } \\
\text { PLT }\end{array}$ \\
\hline $3^{\circ}$ & $\begin{array}{l}\text { Aplicação de resíduos celulósicos, como auxiliar de tratamento de } \\
\text { efluentes contendo cromo hexavalente }\end{array}$ & CE3b & - & S & S & - \\
\hline $3^{\circ}$ & $\begin{array}{l}\text { Grandes problemas, pequenas soluções: nano-repelentes na prote- } \\
\text { ção contra os mosquitos }\end{array}$ & CE3c c & - & S & N & PLT \\
\hline $3^{\circ}$ & Sistema de monitoramento do nível de água do lençol freático & CE3d & - & S & S & - \\
\hline $4^{\text {o }}$ & VITAE - carteira de vacinação digital & CE4a & S & S & N & PP \\
\hline $4^{\text {o }}$ & Produção de papel a partir de plantas não lenhosas & CE4b & S & N & N & - \\
\hline $4^{\text {o }}$ & $\begin{array}{l}\text { Desenvolvimento de um aplicativo de realidade aumentada para o } \\
\text { auxílio do ensino da biologia no ensino fundamental e médio }\end{array}$ & CE4c & S & N & N & PLT \\
\hline $4^{\text {o }}$ & Lest e Lazu: plataformas tecnológicas educacionais & CE4d & S & N & N & PLT \\
\hline
\end{tabular}

Fonte: Elaboração própria.

Novamente obtemos aqui a maioria dos projetos identificados como possíveis patentes e/ou comercializáveis, como observado nas áreas apresentadas anteriormente, principalmente em Ciências Agrárias e Ciências Biológicas. Assim como em CS4a, o projeto CE3a elaborou um protótipo, dando margens à necessidade de estudos mais aprofundados antes de sua implantação no mercado ou disponibilização à população. CE3b e CE3d não apresentaram resultados em seu resumo, portanto, não inferimos sua possibilidade de comercialização/patente nem se seguem PP ou PLT.

Embora CE3c não tenha apresentado qualquer resultado de sua pesquisa no resumo, é um projeto que prevê a utilização de nanotecnologia, uma área da pesquisa que, segundo Lacey (2009b), pode ser eticamente irresponsável, visto que pode ocasionar mudanças e alterações ecológicas e socais drásticas, a não ser que seja realizado pesquisas rigorosas e sistemáticas a fim de verificar consequências ecológicas e sociais a longo prazo, levando em conta inclusive as condições socioeconômicas das implementações planejadas e as condições de seu uso. Uma reflexão extremamente necessária aqui e no âmbito das pesquisas desenvolvidas desde a educação básica.

Já o projeto CE4a traz clara possibilidade de comercialização, mas também inclui em si um valor social:

[...] o aplicativo institucional VITAE, direcionado a população, disponibiliza o calendário completo de acordo com o SUS, bem como informações sobre a importância da vacinação. Considera-se que a dinamização da saúde pública no Brasil é fundamental para que sua atual ascensão não seja somente econômica, mas também social. (FEBRACE, 2017, p. 77)

Ainda para CE4a verificamos sua atenção à forma de utilização do aplicativo, um princípio de precaução (PP), conforme consta:

O sistema, primeiramente, ficará hospedado nos postos de saúde. Através dele, é possível cadastrar pacientes, bem como atrelá-los às vacinas já aplicadas, uma vez que todas as informações sobre tais vacinas são dispostas em tabelas dinâmicas através de cores, individualmente destacadas para cada paciente (FEBRACE, 2017, p. 77).

\section{Ciências Humanas}

Com um total de 41 projetos finalistas em Ciências Humanas $(\mathrm{CH})$, sete foram premiados, conforme mostra o Quadro 5. 
Quadro 5 - Lista de projetos premiados em Ciências Humanas pela FEBRACE 2017 e inferências quanto às questões acima apresentadas.

\begin{tabular}{|c|c|c|c|c|c|c|}
\hline \multirow{2}{*}{ Lugar } & \multirow[b]{2}{*}{ Projeto } & \multirow[b]{2}{*}{ Sigla } & \multicolumn{4}{|c|}{ Questões } \\
\hline & & & 1 & 2 & 3 & 4 \\
\hline $1^{\circ}$ & $\begin{array}{l}\text { Os atores políticos do poder executivo jaguaribano: ações, memórias } \\
\text { e imagem pública (1972-2012) }\end{array}$ & $\mathrm{CH} 1$ & $\mathrm{~N}$ & $\mathrm{~N}$ & $\mathrm{~N}$ & - \\
\hline $2^{\circ}$ & $\begin{array}{l}\text { Justiça de transição e a Lei da Anistia: análise do caso brasileiro do } \\
\text { século XX e XXI }\end{array}$ & $\mathrm{CH} 2 \mathrm{a}$ & $\mathrm{N}$ & S & $\mathrm{N}$ & - \\
\hline $2^{\circ}$ & $\begin{array}{l}\text { Ubuntus: audiovisual para pensar a cultura africana, sua herança para } \\
\text { a cultura brasileira e para o progresso técnico, e direitos humanos }\end{array}$ & $\mathrm{CH} 2 \mathrm{~b}$ & $\mathrm{~N}$ & $\mathrm{~N}$ & $\mathrm{~N}$ & - \\
\hline $3^{\circ}$ & Honestidade: moldada ou herdada? & $\mathrm{CH} 3 \mathrm{a}$ & $\mathrm{N}$ & S & $\mathrm{N}$ & - \\
\hline $3^{\circ}$ & $\begin{array}{l}\text { Arte ativa: empoderamento feminino com jovens do ensino } \\
\text { fundamental } 2\end{array}$ & $\mathrm{CH} 3 \mathrm{~b}$ & $\mathrm{~N}$ & S & S & - \\
\hline $4^{\circ}$ & Roteiro turístico ambiental, cultural e religioso de Maranguape II & $\mathrm{CH} 4 \mathrm{a}$ & $\mathrm{N}$ & $\mathrm{N}$ & S & - \\
\hline $4^{\circ}$ & $\begin{array}{l}\text { Tabela periódica com geometria semiesférica em Braille: uma ferra- } \\
\text { menta alternativa para a melhoria do ensino da química para alunos } \\
\text { deficientes visuais }\end{array}$ & $\mathrm{CH} 4 \mathrm{~b}$ & S & S & $\mathrm{N}$ & - \\
\hline
\end{tabular}

Fonte: Elaboração própria.

Fica evidente nessa área, Ciências Humanas, a diferença dentre as demais devido ao se enquadrarem melhor, em sua maioria, nas condições não patenteável e/ou comercializável. Lacey (2008b, p. 217) diz que as Ciências Humanas visam o entendimento do comportamento humano, suas capacidades cognitivas e "relações sociais em termos de sua geração pelas estruturas e leis subjacentes multiplicaram-se durante este século". CH3a, por exemplo, pesquisa o comportamento humano, iniciando seu resumo falando que o princípio da ética é a honestidade, sendo seu objetivo "resgatar a conscientização sobre as atitudes e ressaltar a importância de se trabalhar o valor da honestidade para formação do ser humano" (FEBRACE, 2017a, p. 243). Como resultado, confirma que a formação do caráter humano é influenciada pelo meio e ao longo da vida sofre alterações na formação, além de mostrar ser importante a retomada constante de princípios éticos.

O estudo do $\mathrm{CH} 3 \mathrm{~b}$ também trata sobre comportamento humano, empoderamento social, visa desenvolver uma consciência crítica e transformadora de maneira a impulsionar a melhoria da qualidade de vida das pessoas e até mesmo o desenvolvimento sustentável. O resumo menciona ainda que esse é um dos fundamentos para "uma sociedade mais igualitária" (FEBRACE, 2017a, p. 235). O desenvolvimento da proposta foi feito com os anos finais do ensino fundamental, mas os autores não apresentaram, nesse momento, seus resultados.

A proposta desse resumo vai ao encontro da questão aclamada por Lacey (2008b, p. 187): "quais deveriam ser os mecanismos curriculares para o desenvolvimento de tal autoconsciência crítica" ao mostrar a relevância da educação científica que não consiste apenas em conhecimento, teorias, habilidade, metodologias, práticas apropriadas à pesquisa, nem dar competência para avaliar quais teorias são corretamente aceitas.

No projeto $\mathrm{CH} 4 \mathrm{a}$, o âmbito turístico do município de Maranguape incluiu a educação ambiental como um ponto importante, assim apresenta seus resultados abrangendo a prática social e a ética ambiental:

[...] foi abordada a educação ambiental, que é uma dimensão da educação, uma atividade que induz no desenvolvimento dos indivíduos um caráter social em sua interação com a natureza e com os seres humanos. Com isso, objetiva a educação ambiental maximizar essa atividade humana, de forma a recobri-la de efetiva prática social e ética ambiental. (FEBRACE, 2017a, p. 263). 


\section{Ciências Sociais Aplicadas}

Com 29 projetos finalistas em Ciências Sociais Aplicadas (CSA), cinco desses foram premiados (quadro 6).

Quadro 6 - Lista de projetos premiados em Ciências Sociais Aplicadas pela FEBRACE 2017 e inferências quanto às questões acima apresentadas.

\begin{tabular}{|c|c|c|c|c|c|c|}
\hline \multirow[b]{2}{*}{ Lugar } & \multirow[b]{2}{*}{ Projeto } & \multirow[b]{2}{*}{ Sigla } & \multicolumn{4}{|c|}{ Questões } \\
\hline & & & 1 & 2 & 3 & 4 \\
\hline $1^{\circ}$ & $\begin{array}{l}\text { Semiárido sustentável: reinventando ações de convivência com a } \\
\text { seca }\end{array}$ & CSA1 & S & S & S & PLT \\
\hline $2^{\circ}$ & $\begin{array}{l}\text { Microcrédito e banco comunitário em Paraisópolis e sua } \\
\text { importância para a economia local }\end{array}$ & CSA2 & $\mathrm{N}$ & S & $\mathrm{N}$ & - \\
\hline $3^{\circ}$ & $\begin{array}{l}\text { Liga da ciência: utilização de desenhos e brinquedos para a } \\
\text { introdução do método científico no ambiente escolar }\end{array}$ & CSA3 & S & $\mathrm{N}$ & $\mathrm{N}$ & PLT \\
\hline $4^{\circ}$ & Indicador de hiperexposição dos jovens nas redes sociais & CSA4a & S & $\mathrm{N}$ & $\mathrm{N}$ & PLT \\
\hline $4^{\circ}$ & Device city: ferramenta de auxílio ao planejamento e gestão urbana & CSA4b & S & $\mathrm{N}$ & $\mathrm{N}$ & PLT \\
\hline
\end{tabular}

Fonte: Elaboração própria.

O projeto CSA1 foi incluído como potencial para comercialização ao mencionar "a criação de uma mandala de baixo custo" e finalizar seu resumo com a afirmação: "É uma tecnologia social, proativa, de baixo custo e com alto poder de replicação" (FEBRACE, 2017a, p. 223). Vemos aqui uma aproximação com o que Lacey (2008b, p. 213) denomina de "tecnologia apropriada", em que seus usuários, "em comunidade, têm controle sobre sua produção e uso, e sobre suas condições materiais [...], de tal modo que sua produção e uso são dirigidos à satisfação das necessidades da comunidade", envolvendo o conhecimento técnico e o conhecimento local, ou seja, ele é considerado como contextualizado. Segundo o autor, são "estratégias que possibilitam a investigação dos objetos na medida em que eles são inseparáveis dos seus contextos" (LACEY, 2019, p. 97).

Em CSA1 também inclui propostas agroecológicas e se preocupam com o fortalecimento da agricultura familiar, sendo essa uma forte discussão trazida por Lacey (2000; 2008b) ao defender a agroecologia e trazer críticas à proposta da revolução verde, que "serviu aos interesses do mercado em vez de a outras concepções de justiça social" (2008b, p. 205).

\section{Engenharia}

A área de Engenharia (E) certamente é a mais evidenciada na FEBRACE, com maior número de projetos participantes (91), sendo algo comumente esperado, já que sua organização parte da Escola Politécnica da USP, ou seja, das Engenharias. Ao todo foram 15 premiações, conforme mostra o Quadro 7.

Quadro 7 - Lista de projetos premiados em Engenharia pela FEBRACE 2017 e inferências quanto às questões acima apresentadas.

\begin{tabular}{|c|c|c|c|c|c|c|}
\hline \multirow[b]{2}{*}{ Lugar } & \multirow[b]{2}{*}{ Projeto } & \multirow[b]{2}{*}{ Sigla } & \multicolumn{4}{|c|}{ Questões } \\
\hline & & & 1 & 2 & 3 & 4 \\
\hline $1^{\circ}$ & SmartLeg - prótese transfemoral inteligente II & E1a & S & S & $\mathrm{N}$ & PLT \\
\hline $1^{\circ}$ & $\begin{array}{l}\text { Interface cérebro-computador de loop fechado hospedada em sis- } \\
\text { tema de computação distribuída para comunicação com pessoas } \\
\text { inicialmente classificadas em estado vegetativo ou coma }\end{array}$ & E1b & S & S & $\mathrm{N}$ & - \\
\hline $1^{\circ}$ & JustStep - piso tátil integrado a comando de voz & E1c & S & $\mathrm{N}$ & $\mathrm{N}$ & PLT \\
\hline $2^{\circ}$ & Manibus - acessório para cadeirante & E2a & S & S & $\mathrm{N}$ & - \\
\hline
\end{tabular}




\begin{tabular}{l|l|l|l|l|l|l}
\hline $2^{\circ}$ & Prótese mioelétrica de baixo custo & E2b & S & S & N & $\begin{array}{l}\text { PP/ } \\
\text { PLT }\end{array}$ \\
\hline $2^{\circ}$ & Haptikos: colete háptico II & E2c & S & N & N & PLT \\
\hline $2^{\circ}$ & $\begin{array}{l}\text { Inibição de melatonina por estímulo luminoso no término do clico } \\
\text { do sono REM }\end{array}$ & E2d & S & N & N & $\begin{array}{l}\text { PP/ } \\
\text { PLT }\end{array}$ \\
\hline $3^{\circ}$ & $\begin{array}{l}\text { Recuperação de membros paralisados por meio da ativação } \\
\text { artificial dos músculos }\end{array}$ & E3a & S & N & N & PLT \\
\hline $3^{\circ}$ & $\begin{array}{l}\text { Estudo da agregação de lignina da palha de milho na produção de } \\
\text { bioplástico e resinas poliméricas }\end{array}$ & E3b & S & N & S & $\begin{array}{l}\text { PP/ } \\
\text { PLT }\end{array}$ \\
\hline $3^{\circ}$ & $\begin{array}{l}\text { STAC-IBR: solução para o tratamento de água nas cisternas } \\
\text { instaladas no Brasil }\end{array}$ & E3c & S & S & N & $\begin{array}{l}\text { PP/ } \\
\text { PLT }\end{array}$ \\
\hline $3^{\circ}$ & $\begin{array}{l}\text { SIADAPT - sistema de identificação e alerta de disponibilidade } \\
\text { para assentos preferenciais de trens }\end{array}$ & E3d & S & N & N & - \\
\hline $4^{\circ}$ & $\begin{array}{l}\text { Controle e interface de veículo aéreo não tripulado em voo } \\
\text { autônomo, para aplicação na agricultura de precisão }\end{array}$ & E4a & S & S & N & PLT \\
\hline $4^{\circ}$ & $\begin{array}{l}\text { Aplicação da Fun Theory para coleta de bitucas de cigarro e estudo } \\
\text { do seu processo de reciclagem }\end{array}$ & E4b & S & N & S & PLT \\
\hline $4^{\circ}$ & $\begin{array}{l}\text { Pantanal iron brick: estudo da viabilidade da adição de rejeito de } \\
\text { minério de ferro na argila plástica da região do Pantanal-MS }\end{array}$ & E4c & S & N & S & PLT \\
\hline $4^{\circ}$ & \begin{tabular}{l} 
DSR - destilador solar de água robotizado \\
\hline
\end{tabular} & E4d & S & N & S & $\begin{array}{l}\text { PP/ } \\
\text { PLT }\end{array}$ \\
\hline
\end{tabular}

Fonte: Elaboração própria.

A área de Engenharia foi a que apresentou maior quantidade de protótipos, como em E1a, que relata que este deverá ser testado apenas em relação ao funcionamento do sistema. . Já o E2a, elabora um protótipo, mas não apresenta resultados quanto a ele, mas sim acerca da carência de acessórios que auxilie em tarefas simples para cadeirantes. E2b, E2d, E3b, E3c e E4d também elaboram protótipo. Já E3d denomina-se de "exemplar embrionário" (FEBRACE, 2017a, p. 347), dificultando a nossa inferência.

Em E4b, mesmo verificando que poucas bitucas foram coletadas, consideram que essas puderam comprovar a eficiência de seu novo coletor, evidenciando a possível comprovação de nossa inferência ao atribuir PLT ao projeto. Da mesma forma observamos o projeto E1c, que relata a produção de um "protótipo final com grande potencial de aplicação, por conta da sua eficiência nos testes e custo-benefício, possibilitando sua utilização em interiores além do ambiente de ensino" (FEBRACE, 2017a, p. 321).

Cabe ressaltar a preocupação colocada por E2b em seu objetivo: “desenvolver próteses mioelétricas destinadas a quem teve amputação no antebraço e não tem condições financeiras favoráveis para adquirir alguma das que estão presentes no mercado atualmente" (FEBRACE, 2017a, p. 336). A ideia de poder oferecer um produto mais barato aqui não significa que isso realmente acontecerá, nem tão pouco que a população carente terá acesso a ela. Mas colocar essa reflexão em evidência traz indícios de um interesse social acima de um capitalista.

Em E3b verificamos a preocupação ambiental e o resumo liga claramente o mercado ao produto sustentável, mas não cita a possibilidade de mais pesquisas para análise de potenciais riscos. O E3c parte do contexto da falta de água, colocando em sua palavra-chave o "semiárido brasileiro", mesmo sendo uma instituição de São Paulo e "propõe o desenvolvimento de equipamento de cloração da água com baixo custo", incluindo para residências que não tem acesso à energia elétrica (FEBRACE, 2017a, p. 356), dando indícios da associação de valores sociais ao projeto.

A E4a finaliza suas colocações com garantias um tanto quanto abrangentes ao concluir: "evitando o desperdício de insumos agrícolas e excesso de agrotóxicos nos alimentos, acarretando uma melhor e mais eficiente alimentação para toda população e, em geral, otimizando o meio agrícola" (FEBRACE, 2017a, p. 
294). Tais colocações evidenciam a aceitação do princípio do pressuposto da legitimidade das inovações tecno científicas (PLT) e, portanto, sua falta de contestação. Isso é apontado por Lacey:

PLT é associado ao quase imperativo ético: priorizar as "soluções" tecnocientíficas para os grandes problemas mundiais, como, por exemplo, a desnutrição nos países pobres; e implica que é uma deficiência ética não só que se coloque em dúvida o potencial ou a legitimidade da pesquisa e do desenvolvimento que possam conduzir a tais "soluções", mas também que se concentre a pesquisa nas relações socioeconômicas envolvidas na implementação das "soluções" (LACEY, 2007, p. 3).

Nesse sentido, Lacey (2007) relata que esse contexto de mudança nas relações de produção do conhecimento científico para a prática sob controle de interesses privados e comerciais resulta que a maioria das pesquisas tecno científicas são empreendidas à luz do PLT.

Caminhando para a finalização de nossa análise, o Gráfico 1 revela um panorama geral e quantitativo

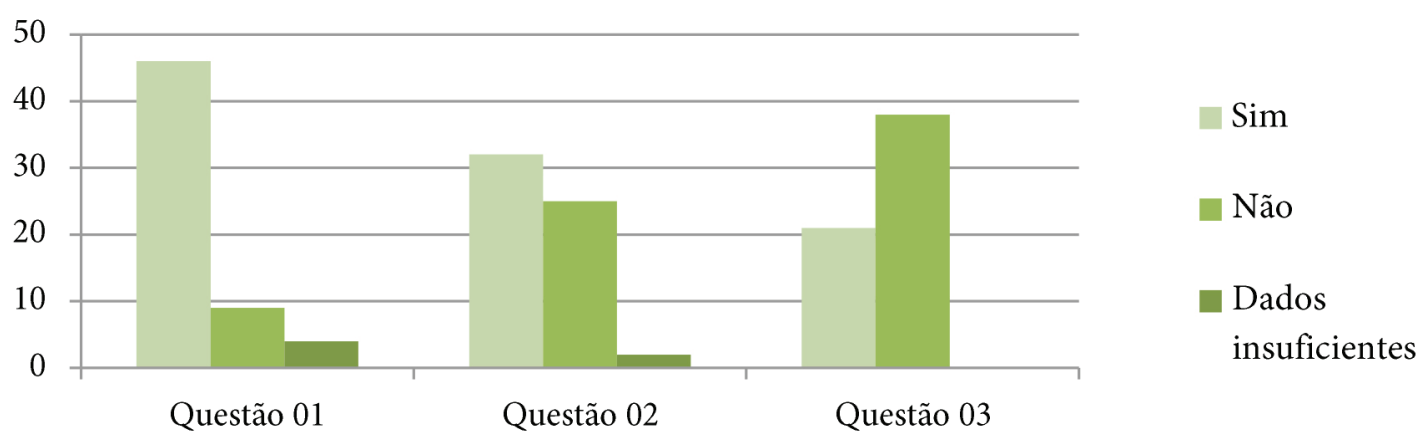

Fonte: Elaboração própria.

Essa expressiva quantidade maior em relação ao interesse comercial foi destaque em nossa análise, já que a maioria dos projetos premiados possui possibilidade comercial e/ou patente, exceto para área de Ciências Humanas. Esse é um resultado que aproxima tais produções tecnocientíficas à tendência ao "desenvolvimento modernizador", em que Lacey relata que "os processos de desenvolvimento envolvem crescimento econômico, industrialização, transferência de tecnologia moderna, integração à economia capitalista mundial” (2008b, p. 200). Essa ênfase vincula-se à inovação tecnocientífica, crescimento econômico, interesses comerciais e utilidade prática (LACEY, 2009a; 2009b; 2012).

Nesse ponto de vista, a FEBRACE mostra indícios na valorização do desenvolvimento modernizador ao incluir a criatividade, inovação e atitude empreendedora em seus critérios de avaliação, além de citar que durante seu percurso, pode observar que alguns estudantes montaram suas empresas "com produtos desenvolvidos a partir das ideias e protótipos apresentados na feira” (FEBRACE, 2017b, p. 2).

Em relação à questão dois, destacamos o projeto CS1, que, mesmo inferindo um possível fim comercial, verificamos uma aproximação com o que Lacey (2008b) denomina de tecnologia apropriada, além de incluir propostas agroecológicas e se preocuparem com o fortalecimento da agricultura familiar. Lacey coloca que para o desenvolvimento autêntico:

[...] o que é bem definido não é o desenvolvimento, mas a condição presente dos empobrecidos, que pode ser empiricamente mapeada e teorizada em termos de noções tais como opressão e dependência. Sua medida não pode ser o progresso material ou o crescimento econômico como tais, e a inovação tecnológica relativamente independente e desimpedida não pode ser sua força propulsora (LACEY, 2008b, p. 200 e 201). 
É válido destacar novamente que um dos critérios de avaliação da FEBRACE é que ela possui extrema relevância social, no entanto, Lacey (2009b) critica que os objetivos e as finalidades da Ciência Aplicada nunca tiveram como prioridade favorecer ou resolver as problemáticas dos menos favorecidos, ou seja diminuir as desigualdades.

Para a questão três, a maioria dos trabalhos não relatam uma preocupação ambiental e, daqueles que se preocupam, tentam amenizar o próprio problema ambiental ocasionado pela ação humana ao explorar os recursos naturais (E4c), ou por produzir poluentes como plásticos (exemplos visto nos resumos CA1 e CB2a) ou para amenizar resultados provindos das indústrias (CE1b, CA1).

Para esse fato, Lacey (2009b) nomeia como problemas de efeitos colaterais, os quais poderão ser solucionados por novas tecnologias disponíveis. Nossa contribuição nessa questão seria verificar a possibilidade de inclusão de um item voltado à preocupação ambiental dentre os critérios de avaliação das feiras atuais, já que é um valor importante. Visto que segundo Lacey (2009c), a sustentabilidade pode ser um valor de extrema relevância não apenas nos movimentos sociais, mas para a população em geral.

Quanto ao resultado geral para PP e PLT, 29 projetos foram classificados em PLT e 4 em PP, 7 em ambos e em 19 os dados não foram suficientes para inferir tal classificação, confirmando o entendimento de Lacey (2007) ao dizer que grande parte da pesquisa tecnocientífica é realizada de acordo com PLT.

\section{Considerações finais}

Em conclusão, a maioria dos projetos premiados mostraram-se como possivelmente patenteáveis e/ ou comercializáveis, sem preocupação ambiental e seguindo o princípio do pressuposto da legitimidade das inovações tecnocientíficas (PLT). Esses resultados corroboram nossa hipótese, visto que foi perceptível a tendência na valorização da produção científica na educação básica, que caminha em direção ao desenvolvimento modernizador, ligada à economia capitalista mundial, desenvolvida e comprovada por meio de estratégias descontextualizadas. O que acaba deslegitimando e sendo pouco expressivos, estudos que possuam valor social e responsabilidade ambiental nas premiações analisadas.

Assim, produções científicas e tecnológicas da educação básica divulgadas em Feiras e Mostras, como a FEBRACE, indicamos a valorização e inserção da preocupação ambiental como um critério de avaliação, além de um olhar mais crítico frente as problemáticas mundiais e locais, entretanto, essas preocupações e valorizações são apenas superficiais e acabam sempre por prestigiar os aspectos financeiros em detrimento de outros valores como social, ambiental, de redução da vulnerabilidade e das desigualdades. Contexto esse que alerta a necessidade conforme pontuada por Lacey (2008a) de lutar por uma mudança de direção da produção de conhecimento científico e nossos dados indicam que essa discussão precisa ser incluída urgentemente desde a educação básica.

Agradecimentos e apoios

O presente trabalho foi realizado com apoio da Fundação Universidade Federal de Mato Grosso do Sul UFMS/MEC - Brasil e do Instituto Federal de Educação, Ciência e Tecnologia de Mato Grosso do Sul (IFMS). 


\section{Referências Bibliográficas}

AULETE DIGITAL. Dicionário online. Disponível em: <http://www.aulete.com.br/prot\%C3\%B3tipo > Acesso em 31 de jul. 2017.

BARDIN, Laurence. Análise de conteúdo. L. de A. Rego; A. Pinheiro, Trads. 1a edição. São Paulo: Edições 70, 1977. 229 p. BRASIL. Ministério da Educação. Secretaria de Educação Básica. Programa Nacional de Apoio às Feiras de Ciências da Educação Básica - Fenaceb. Brasília, DF: MEC, 2006.

FEIRA BRASILEIRA DE CIÊNCIA E ENGENHARIA. 15º, 2017a, São Paulo. Anais. São Paulo: EPUSP, 2017 a. 451 p. FEIRA BRASILEIRA DE CIÊNCIA E ENGENHARIA. 15², 2017b, São Paulo. Relatório de Atividades. São Paulo: EPUSP, 2017b. 96 p.

FEIRA BRASILEIRA DE CIÊNCIA E ENGENHARIA. Site institucional. Disponível em < http://febrace.org.br $>$ Acesso em jul. 2017c.

GERMANO, Marcelo Gomes. Uma nova ciência para um novo senso comum [online]. Campina Grande: EDUEPB, 2011. 400 p.

KRASILCHIK, Myriam. Reformas e realidade: o caso do ensino das ciências. São Paulo em Perspectiva, São Paulo, v. 14, n. 1, p. 85-93, 2000.

LACEY, Hugh. As sementes e o conhecimento que elas incorporam. São Paulo em Perspectiva, São Paulo, v. 14, n. 3, p. 53-59, 2000.

LACEY, Hugh. O princípio de precaução e a autonomia da ciência. Scientiae Studia, São Paulo, v. 4, n. 3, p. 373-392, 2006.

LACEY, Hugh. Os valores da ciência e o papel da ética na ciência. In: Reunião Anual da Sociedade Brasileira Para o Progresso da Ciência, 59, 2007, Belém/PA. Anais... Belém do Pará: SBPC, 2007. p. 01-03.

LACEY, Hugh. Ciência, respeito à natureza e bem-estar humano. Scientiae Studia, São Paulo, v. 6, n. 3, p. 297-327, 2008a.

LACEY, Hugh. Valores e atividade científica I. São Paulo: Associação Filosófica Scientiae Studia/Editora 34, 2008 b. 296 p.

LACEY, Hugh. Ética e Ciência. In: Reunião Anual da Sociedade Brasileira para o Progresso da Ciência, 61, Manaus/ AM. Anais... Manaus: SBPC, 2009a. p. 01-03.

LACEY, Hugh. La ética y el desarrollo de la nanotacnología. Revista Realidad, La Rioja, n. 119, p. 77-90, 2009b.

LACEY, Hugh. Entrevista: Hugh Lacey. Trabalho, Educação e Saúde, Rio de Janeiro, v. 7, n. 3, p. 623-628, nov. 2009c. Entrevista concedida à revista.

LACEY, Hugh. Reflections on Science and technoscience. Scientiae Studia, São Paulo, v. 10, n. spe, p. 103-128, 2012.

LACEY, Hugh. Ciência, valores, conhecimento tradicional/indígena e diálogo de saberes. Desenvolvimento e Meio Ambiente. Curitiba, v. 50, Diálogos de Saberes Socioambientais: desafios para epistemologias do Sul, p. 93-115, abril 2019.

NASCIMENTO, Fabrício do; FERNANDES, Hylio Laganá; MENDONÇA, Viviane Melo de. O Ensino de Ciências no Brasil: história, formação de professores e desafios atuais. Revista HISTEDBR On-line, Campinas, v. 10, n. 39, p. 225-249, set. 2010. 